\title{
Periodic autonomic dysfunction without pain in a patient with cluster headache
}

\author{
Avi Ashkenazi \\ Thomas Jefferson University \\ Stephen Silberstein \\ Thomas Jefferson University
}

Follow this and additional works at: https://jdc.jefferson.edu/neurologyfp

Part of the Neurology Commons

Let us know how access to this document benefits you

\section{Recommended Citation}

Ashkenazi, Avi and Silberstein, Stephen, "Periodic autonomic dysfunction without pain in a patient with cluster headache" (2004). Department of Neurology Faculty Papers. Paper 6. https://jdc.jefferson.edu/neurologyfp/6

This Article is brought to you for free and open access by the Jefferson Digital Commons. The Jefferson Digital Commons is a service of Thomas Jefferson University's Center for Teaching and Learning (CTL). The Commons is a showcase for Jefferson books and journals, peer-reviewed scholarly publications, unique historical collections from the University archives, and teaching tools. The Jefferson Digital Commons allows researchers and interested readers anywhere in the world to learn about and keep up to date with Jefferson scholarship. This article has been accepted for inclusion in Department of Neurology Faculty Papers by an authorized administrator of the Jefferson Digital Commons. For more information, please contact: JeffersonDigitalCommons@jefferson.edu. 
Periodic Autonomic Dysfunction without Pain in a Patient with Cluster Headache Avi Ashkenazi, M.D. and Stephen D. Silberstein, M.D.

Cluster headache $(\mathrm{CH})$ is characterized by episodes of severe unilateral headache accompanied by symptoms of cranial parasympathetic hyperactivity and sympathetic dysfunction that occur in cluster periods (1). Positron emission tomography (PET) studies have demonstrated evidence of a central generator of $\mathrm{CH}$ attacks located in the posteriorinferior hypothalamus $(2,3)$. It has been suggested that the autonomic symptoms in $\mathrm{CH}$ result from reflex activation of the superior salivatory nucleus secondary to activation of the trigeminal nucleus caudalis (TNC) (4). However, several cases of $\mathrm{CH}$-like symptoms with no head pain have been documented $(5,6)$.

We describe a patient who had suffered from typical episodic $\mathrm{CH}$ for two decades; it later converted into episodic autonomic dysfunction without head pain.

\section{Case report}

The patient is a 41-year-old man who had had episodic $\mathrm{CH}$ for 20 years. A typical attack consisted of a severe (10/10) drilling pain in the right retro-orbital and temporal areas and right jaw. The pain was associated with nausea and photophobia. During an attack, he had tearing, conjunctival injection, and ptosis on the right, as well as a congested nostril on the same side. He would have eight attacks per 24 hours, with each attack lasting 3045 minutes. They occurred day and night. Cluster periods occurred once every two years and lasted two to three weeks. A head MRI was normal. Oxygen or dihydroergotamine were effective for acute attacks. Verapamil $480 \mathrm{mg} /$ day was effective in reducing the 
frequency and severity of attacks. He smoked two packs of cigarettes a day for the last 23 years and occasionally drank alcoholic beverages.

In December 2003 the patient was seen at our outpatient clinic for a follow-up visit. At this point, he had tapered his verapamil to $80 \mathrm{mg} /$ day. He stated that he had no headaches, but continued to have episodes of tearing, eye-lid drooping and congested nostril on the right. The episodes would occur twice a day and last for approximately five minutes. Some occurred at night at approximately 2:00 am, the same time as his typical cluster headaches had occurred. He did not take any medications for these episodes. His physical and neurologic examinations were normal.

On a follow-up call the patient reported that these episodes ceased after a period of four weeks.

\section{Discussion}

This patient had typical episodic $\mathrm{CH}$ for two decades before the pain component of his attacks stopped. This sequence of events in $\mathrm{CH}$ has not been previously described. Salvesen described a case of a young man with episodes of unilateral miosis, ptosis, and nasal congestion without pain. Six years later the patient had the same symptoms, this time accompanied by severe unilateral headache, completing the picture of episodic $\mathrm{CH}$ (5). Our patient had a reverse sequence of events, with the full $\mathrm{CH}$ picture occurring first and loss of the pain component years later. Both cases support the notion that isolated 
autonomic dysfunction, occurring in a typical temporal course, is part of the $\mathrm{CH}$ clinical spectrum.

The literature further supports this notion. In a recent report, Leone et al described a woman who had episodic unilateral cranial autonomic symptoms that occurred in clusters that lasted 20-30 days (6). Her son had typical episodic $\mathrm{CH}$. The occurrence of these two clinical pictures in one family supports (albeit does not prove) the assumption that they are related.

Sjaastad et al described a patient who had a history of $\mathrm{CH}$ with autonomic dysfunction contralateral to the side of the head pain (7). This case and ours show that the autonomic dysfunction in $\mathrm{CH}$ may be separated from the head pain in time or location. These observations suggest that the autonomic symptoms in $\mathrm{CH}$ are not secondary to the pain but an independent phenomenon.

Our observation does not support the concept that a trigemino-parasymapthetic reflex, introduced by Goadsby, can explain the combination of pain and cranial autonomic dysfunction in all cases of $\mathrm{CH}$ and other headaches (4). Rather, it shows that the two components of these headaches can occur independently. The fact that the episodes of autonomic dysfunction without pain were more brief than the ones that occurred with head pain suggests that the pain, when present, can prolong the parasympathetic activation during $\mathrm{CH}$ attack. Pain, however, is not necessary for the autonomic symptoms to occur.

Recent functional imaging studies show activation of the posterior-inferior hypothalamus during a $\mathrm{CH}$ attack $(2,3)$. This area may be the generator of both the pain and the autonomic symptoms in $\mathrm{CH}$. Some patients, however, may have only one of these two 
components activated during an attack. The mechanism that leads to this limited expression of $\mathrm{CH}$ attack is still to be determined.

\section{REFERENCES}

1. Dodick DW, Campbell JK. Cluster headache: diagnosis, management, and treatment. In: Silberstein SD, Lipton RB, Dalessio D, editors. Wolff's Headache and Other Head Pain. 7th ed. New York: Oxford University Press, 2001: 283-309

2. May A, Bahra A, Buchel C, Frackowiak RS, Goadsby PJ. Hypothalamic activation in cluster headache attacks. Lancet 1998;352:275-8

3. May A, Bahra A, Buchel C, Frackowiak RS, Goadsby PJ. PET and MRA findings in cluster headache and MRA in experimental pain. Neurology 2000;55:1328-35

4. Goadsby PJ. Cluster headache: new perspectives. Cephalalgia 1999;19:39-41

5. Salvesen R. Cluster headache sine headache: case report. Neurology 2000;55:451

6. Leone M, Rigamonti A, Bussone G. Cluster headache sine headache: two new cases in one family. Cephalalgia 2002;22:12-4

7. Sjaastad O, Salvesen R, Antonaci F. The sweating anomaly in cluster headache. Further observations on the underlying mechanism. Cephalalgia 1987;7:77-81 